\title{
Power Losses in Outside-Spin Brushless D.C. Motors
}

\author{
P. Andrada, M.Torrent, J.I.Perat, B. Blanqué \\ Departament d'Enginyeria Elèctrica (Universitat Politècnica de Catalunya) \\ EPS d'Enginyeria de Vilanova i la Geltrú \\ Avda. Víctor Balaguer, s/n, 08800 Vilanova i la Geltrú (Spain) \\ Telf.+34 938967732; Fax:+34 938967700, e-mail: andrada@ee.upc.es
}

\begin{abstract}
Outside-spin brushless D.C. motors are an alternative to conventional D.C. brush permanent magnet motors, especially in applications that require low power and costs and in which high inertia effects are advantageous. This paper presents a procedure for computing power losses in these kinds of machines. Expressions are derived for predicting copper losses, power interrupter losses, stator iron losses in the tooth and in the yoke, mechanical losses, friction and windage. Stray load losses are also considered and evaluated from previous measurements in outside-spin brushless D.C. motors. The results obtained from the approach proposed are compared to those measured on existing motors, showing a good agreement.
\end{abstract}

\section{Key words}

Outside-spin motors, brushless D.C. motors, copper losses, iron losses, mechanical losses, stray losses, efficiency.

\section{Introduction}

Outside-spin brushless D.C. motors or brushless D.C. motors with outer rotor have deserved increasing attention in the market of low cost and low power applications that require constant speed, such as motors for fans, motors for office automation (copiers, printers, etc.) and, in general, applications in which high inertia effects are beneficial to the system's performance. These applications, usually powered by permanent magnet D.C. brush motors, demand quieter motors, low EMI levels and require no maintenance. Outside-spin brushless D.C. motors are specially intended for applications that require thin motors (short length and long external diameter). Outside-spin brushless D.C. motors have several advantages over inner-rotor brushless D.C. motors. They have a greater magnet surface, which therefore allows larger airgap and leads to a reduction in mechanical tolerances. In addition, they are less costly to wind. In this paper, a procedure for the determination of power losses in three-phase outside brushless D.C. motors is reported. In this procedure, all kinds of losses (copper, power interrupter, iron, mechanical and stray load losses) are considered and their influence on torque production is studied. This procedure is suitable for design studies that require the fast evaluation of motor performance and in loss evaluation prior to using finite element analysis. The results calculated with the procedure proposed are compared to the experimental results.

\section{Drive Description}

An outside-spin brushless D.C. motor has an electromagnetic structure, which is formed by an outer rotor that has a permanent magnet arrangement enclosed by soft magnetic steel housing and a stator assembly that consists of a lamination stack with coils wrapped around the stator tooth (Fig. 1). Most of its applications are in the low power (up to $250 \mathrm{~W}$ ), low voltage $(12,24 \mathrm{~V}$ ) and moderate speed (slightly over $3000 \mathrm{rpm}$ ) ranges. Thin motor design requires a high number of poles to reduce core back iron and end-windings, and that number is only limited by frequency considerations. If good performance and low torque ripple are drive requirements, a threephase star-connected motor associated with an inverter with six power switches (Power Mosfet, due to the values of voltage and current managed) is the best choice. Usually, three Hall latch sensors are enough for position determination. Low cost requirements mean that ferrite magnets must be used and electric loading must be increased. As a consequence, a large slot area must be adopted. In addition, the power converter and control must find room inside the motor (Fig. 2).

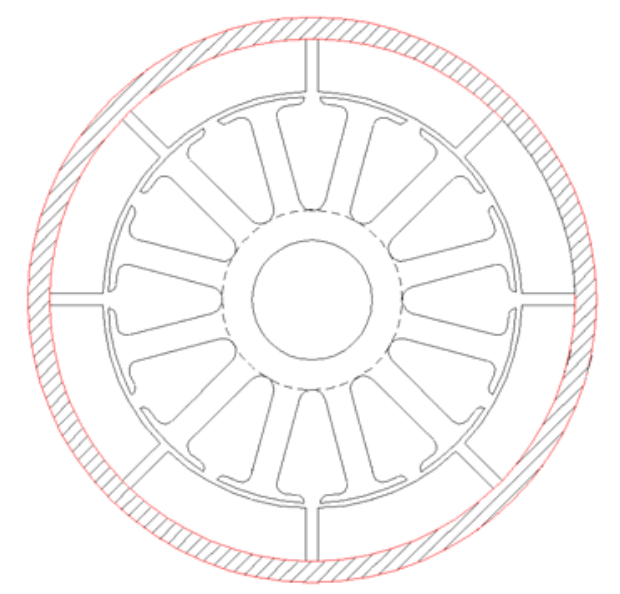

Fig. 1. Cross section of an eight-pole outside-spin brushless D.C. motor 


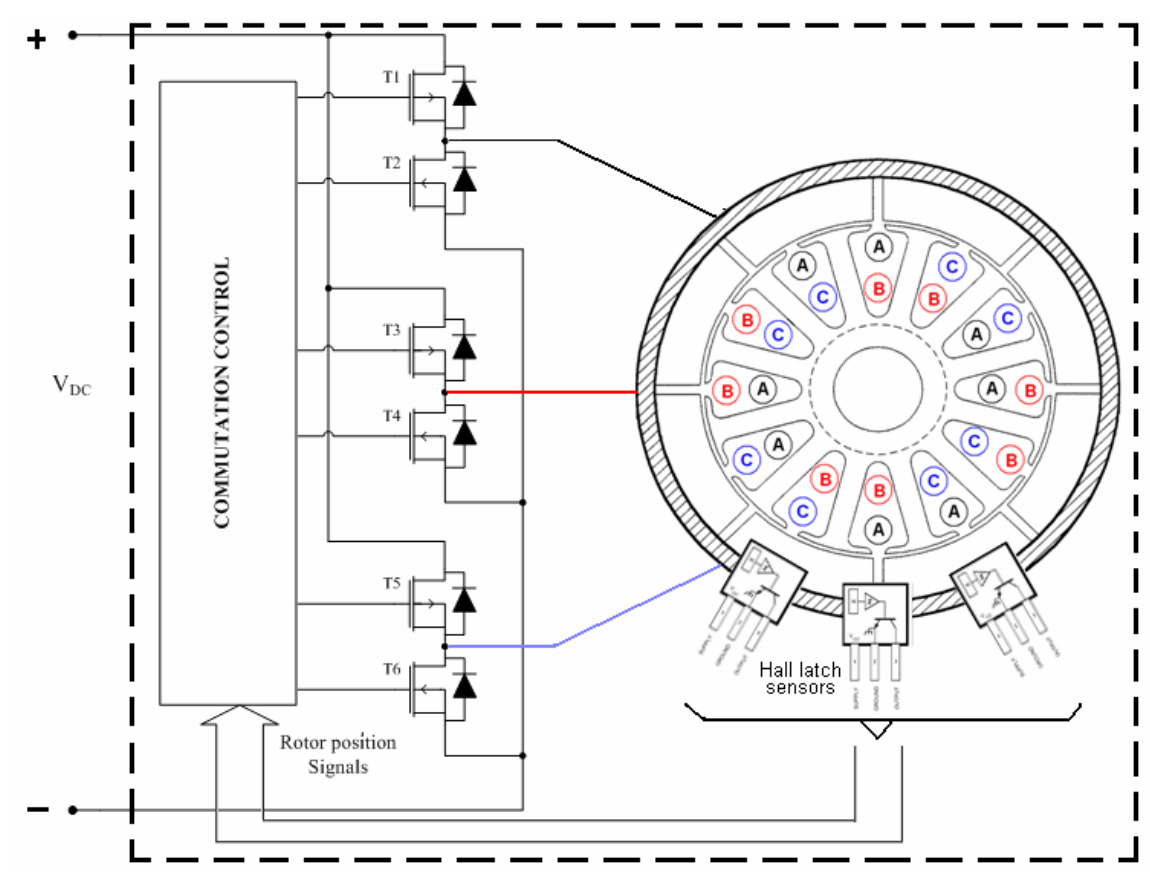

Fig. 2. Block diagram of an outside-spin brushless D.C. motor drive

\section{Determination of Power Losses}

Power losses in electric motors are an important issue because these losses determine the efficiency of the motor and its heating. High efficiency cuts the operating costs, contributes to energy saving and reduces gas emissions. Moderate heating increases safety. High efficiency in outside brushless D.C. motors can offer a competitive advantage over conventional drives. The following expressions are derived in order to predict copper losses, power interrupter losses, stator iron losses in the tooth and in the yoke, mechanical losses, friction and windage. Stray load losses are also considered and evaluated from previous measurements.

\section{A. Copper Losses}

Copper losses at a specified temperature $\theta$ are computed by means of the following equation:

$$
p_{c u \theta}=3 k_{\theta} R_{20^{\circ}} I_{R M S}^{2}(\mathrm{~W})
$$

where $k_{\theta}$ is the temperature correction factor given by:

$$
k_{\theta}=\frac{235+\theta}{255}
$$

Phase resistance is calculated by means of the expression:

$$
R_{20^{\circ}}=\rho_{20^{\circ}} \frac{N_{f}}{s_{c}} l_{e m}(\Omega)
$$

where $\rho_{20^{\circ}}$ is the copper resistivity; $N_{f}$ are the number of turns per phase; $s_{c}$ is the conductor cross section and $l_{e m}$ is the mean coil length.

If we consider, in a first approximation, an ideal $120^{\circ}$ square wave, then:

$$
I_{R M S}=I \sqrt{\frac{2}{3}}(\mathrm{~A})
$$

The I flat top current (A) coincides with the D.C. current input. Equation (4) can be substituted in Equation (1) to give:

$$
p_{c u \theta}=2 k_{\theta} R_{20^{\circ}} I^{2}
$$

Skin effects can be neglected because, in outside-spin D.C. motors in the range considered, the skin depth $\delta$ is usually higher than the wire size $d_{c}$, that is:

$$
\delta=\sqrt{\frac{2 \rho}{\omega \mu_{0}}}>d_{c}
$$

\section{B. Power Interrupter Losses}

If we consider that, in a steady state, there are always two switches in the ON state, the losses across the power interrupters $p_{\text {int }}$, can be evaluated by:

$$
p_{\text {int }}=2 R_{O N} I^{2}(\mathrm{~W})
$$

where $R_{O N}$ is the resistance of the power switch in the ON state. 


\section{Iron Losses}

The specific iron loss for a sinusoidal magnetic field is expressed by means of the well-known Steinmetz equation:

$$
P_{F e}=k_{h} f \hat{B}^{\alpha}+k_{e} f^{2} \hat{B}^{2}(\mathrm{~W} / \mathrm{kg})
$$

where the first term is the hysteresis loss and the second is the specific eddy current loss. $\hat{B}$ is the peak value of flux density and $\beta, k_{h}, \alpha$ and $k_{e}$ are constants determined by curve fitting from the manufacturer's data.

The iron loss expression in (8) is only valid for sinusoidal flux density. In brushless D.C. motors, the variation of flux in the stator core is not sinusoidal. Under these conditions, an alternative approach for specific iron loss is given by:

$$
P_{F e}=k_{h} f \hat{B}^{\alpha}+\frac{k_{e}}{2 \pi^{2}}\left(\frac{d B}{d t}\right)_{R M S}^{2}(\mathrm{~W} / \mathrm{kg})
$$

Note that the hysteresis loss term is unchanged as it depends only on the peak value of the flux density, assuming that there are no minor hysteresis loops. By following this approach, expressions for the iron loss are derived in order to predict the hysteresis and eddy current losses in the stator tooth and in the stator yoke, [1] to [4].

\section{1). Iron Losses in the Stator Teeth}

Specific iron losses in the teeth $p_{t}$, including hysteresis and eddy current losses, can be determined using the following expression:

$$
p_{t}=k_{h} f B_{t}^{\alpha}+\frac{4}{\pi} k_{e} \frac{f^{2} \hat{B}_{t}^{2}}{\alpha_{t t}} \gamma(\mathrm{W} / \mathrm{kg})
$$

where $\hat{B}_{t}$ is the teeth flux density and $\alpha_{t t}$ is the augmented tooth arc that can be expressed by:

$$
\begin{gathered}
\alpha_{t t}=p\left(\frac{\pi}{s}-\frac{k_{c} w_{o}}{D}\right) \text { (elec. rad.) } \\
\text { and } \gamma=1 \text { if } \alpha_{t t} \leq \pi-\beta_{m} \\
\text { or } \gamma=\left(2-\frac{\pi-\beta_{m}}{\alpha t t}\right) \text { (elec. rad.) if } \alpha_{t t}>\pi-\beta_{m}
\end{gathered}
$$

where $s$ is the slot number, $k_{c}$ is the Carter coefficient, $w_{0}$ is the slot opening and $D$ is the stator diameter.

\section{2). Iron Losses in the Stator Yoke}

Specific iron losses in stator yoke $p_{y}$, including hysteresis and eddy current losses, can be determined using the following expression:

$$
p_{y}=k_{h} f B_{y}^{\alpha}+\frac{8}{\pi} k_{e} \frac{f^{2} \hat{B}_{y}^{2}}{\beta_{m}}(\mathrm{~W} / \mathrm{kg})
$$

where $\hat{B}_{y}$ is the yoke flux density and $\beta_{m}$ (elec. rad.) is the magnetic pole arc.

\section{3). Stator Core Loss}

The total iron losses $p_{F e}$ in the stator core, if we ignore surface loss, are calculated by means of the equation:

$$
p_{F e}=p_{t} G_{t}+p_{y} G_{y}(\mathrm{~W})
$$

where $p_{t}$ and $p_{y}$ are the specific losses $(\mathrm{W} / \mathrm{kg})$ in the teeth and stator yoke and $G_{t}$ and $G_{y}$ are the weights $(\mathrm{kg})$ of the tooth and stator yoke respectively.

\section{Mechanical Losses [5]}

The mechanical losses $p_{\text {mec }}$ are subdivided in two parts: friction losses $p_{f r}$ and windage losses $p_{\text {wind }}$ :

$$
p_{\text {mec }}=p_{\text {fr }}+p_{\text {wind }}(\mathrm{W})
$$

Friction losses in bearings can be determined using the following formula:

$$
p_{f r} \approx \frac{3}{2} n_{r} G_{r o t} N \times 10^{-3}(\mathrm{~W})
$$

where $n_{r}$ is the number of bearings, $G_{r o t}$ is the rotor weight, and $N$ is the speed (rpm).

Windage losses are evaluated by the formula:

$$
p_{\text {wind }} \approx 2 D_{\text {out }}^{3} L N^{3} \times 10^{-6}(\mathrm{~W})
$$

where $D_{\text {out }}$ is the outside rotor's diameter (m), and $L$ is the rotor's length $(\mathrm{m})$.

\section{E. Stray Load Losses}

Stray load losses are defined as the losses that arise from the non-uniform distribution of a current in copper. They also encompass additional core losses that are produced in iron by the distortion of magnetic flux by a load current. It is common practice to evaluate stray losses as a percentage ( 3 to $5 \%$ ) of the output power of small machines rated up to $10 \mathrm{~kW}$ [5]. Nevertheless, several tests performed on outside brushless D.C. motors working at constant speed show that these kinds of losses increase markedly with the load and under these conditions frequency has no influence. In addition, current waveforms are not ideal $120^{\circ}$ square waves, which clearly contribute to increasing the amount of copper losses. Therefore, stray load losses can be estimated by means of the following empirical expression: 


$$
p_{s}=2\left(\lambda-\sqrt{\frac{2}{3}}\right) R_{20^{\circ}} I^{x}(\mathrm{~W})
$$

where $\lambda=\frac{I_{R M S}}{I}$ and is usually between 0.86 and 0.84 , and exponent $x$ may be evaluated range from 2.8 to 3.6.

\section{Procedure Verification}

The proposed procedure for determining power losses is applied to an existing eight-pole outside-spin brushless
D.C. motor (Table I). The computed power losses are compared to the data tested. From a non-load test at different speeds, the stator core, windage and friction losses are obtained (Fig. 3). From a load test, in which the outside-spin brushless D.C. motor is connected to a dynamometer, efficiency versus load is reported (Fig. 4). Very good agreement is derived from the non-load test; therefore, the computation of stator core and mechanical losses based on the expressions proposed is suitable for this kind of motor. The efficiency calculated under different load conditions shows significant variations at loads lower than 0.5 p.u., compared to values obtained experimentally, although there is fairly good agreement in the range of 0.5 p.u. to 1.25 p.u.

TABLE I. - Main Characteristics of an Eight-Pole Outside-Spin Brushless D.C. Motor

\begin{tabular}{|l|c|}
\hline Voltage & $12 \mathrm{~V}$ \\
\hline Torque & $20 \mathrm{Ncm}$ \\
\hline Current & $7 \mathrm{~A}$ \\
\hline Speed & $2500 \mathrm{rpm}$ \\
\hline Output diameter & $95 \mathrm{~mm}$ \\
\hline Total length & $40 \mathrm{~mm}$ \\
\hline Permanent magnets & $\begin{array}{c}\text { Ferrites FXD 4 A } \\
\mathrm{Br}=415 \mathrm{mT}\end{array}$ \\
\hline Lamination & $\mathrm{M}-600-65 \mathrm{~A}$ \\
\hline
\end{tabular}

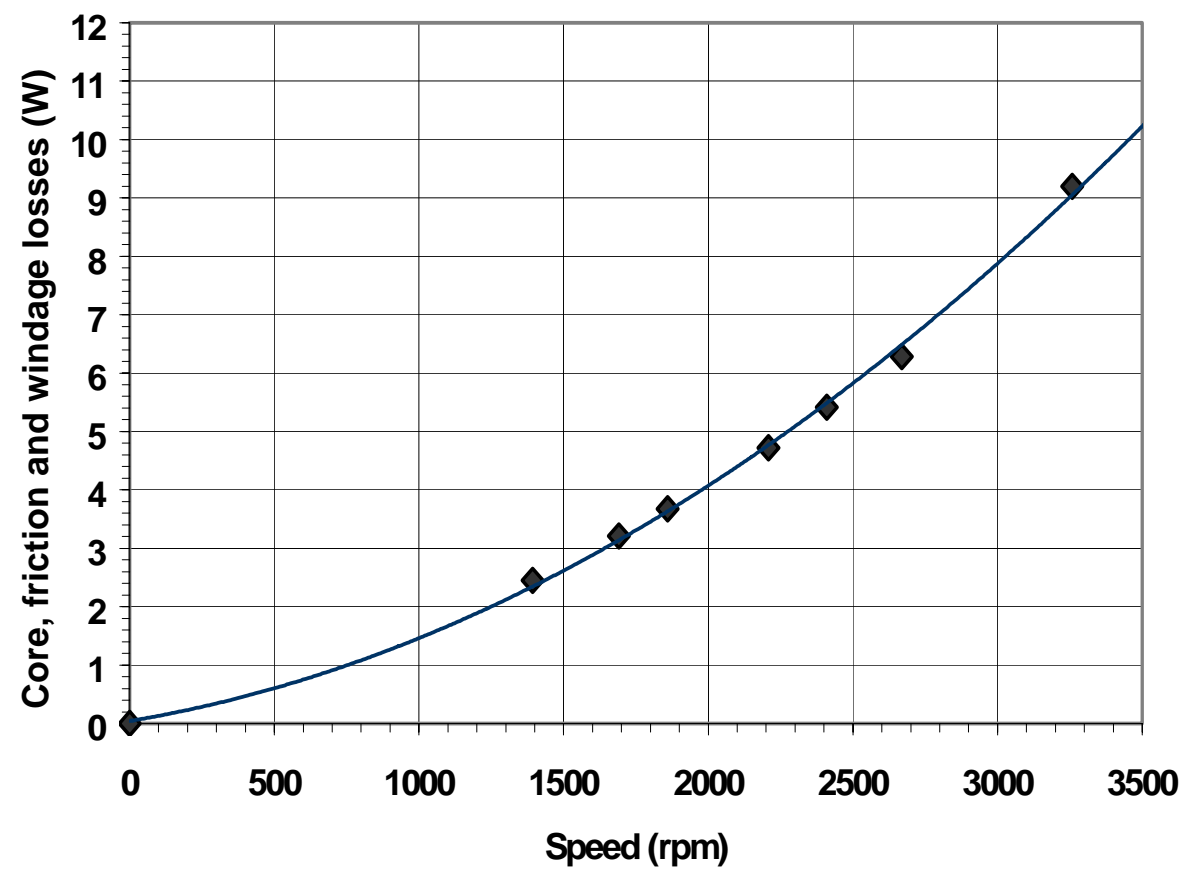

Fig. 3. Core friction and windage losses versus speed. The straight line was obtained using the expressions proposed, and the points were obtained experimentally 


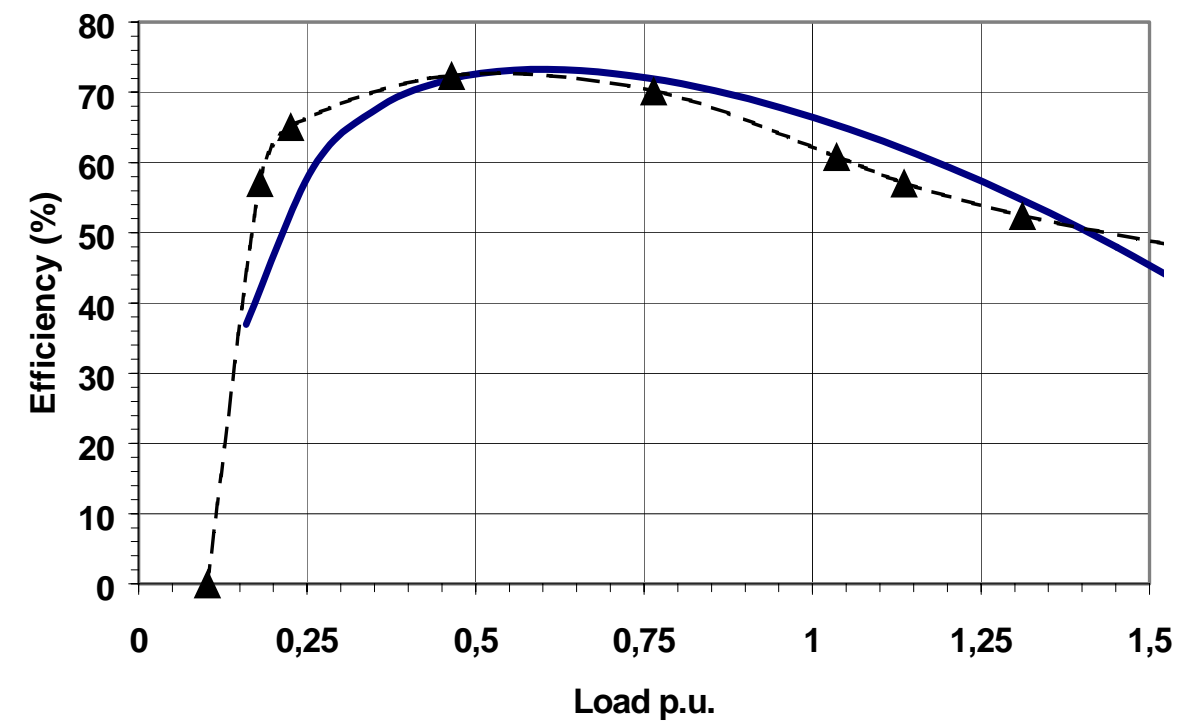

Fig. 4. Efficiency (\%) versus load (p.u.). The straight line was obtained using the expressions proposed, and discontinuous line shows the experimental results

\section{Conclusions}

The paper describes a procedure for power loss determination in outside-spin brushless D.C. motors. In the procedure proposed, expressions are derived for predicting copper losses, power interruption losses, stator iron losses in the tooth and in the yoke, mechanical losses, friction and windage. Stray load losses are also considered and evaluated from previous measurements. Power loss determination using the methodology explained show good agreement with the experimental results obtained from the tests. The procedure proposed is suitable for design studies that require a fast evaluation of motor performance and in loss evaluation prior to using finite element analysis.

\section{Acknowledgement}

The authors would like to thank DOGA S.A., who provided outside-spin brushless D.C. motors for testing and particularly Hans Baudaug and Fermi Lacoma for their support.

\section{References}

[1] T. J. E. Miller and R. Rabinovici. "Back-EMF Waveforms and Core Losses in Brushless D.C. Motors". IEE Proc. Electr. Power Appl., Vol. 141, No. 3, May 1994, pp. 144-154.

[2] G. Slemon and X. Liu. "Core Losses in Permanent Magnet Motors". IEEE Transactions on Magnetics, Vol. 26, No. 5, September 1990, pp. 1653-1655.

[3] C. Mi, G. Slemon, R. Bonert. "Modeling of Iron Losses of Permanent-Magnet Synchronous Motors". IEEE Transactions on Industry Applications, Vol. 19, No. 3, May/June 2003, pp. 734-742.

[4] Deng. "An Improved Iron Loss Estimation for Permanent Magnet Brushless Machines". IEEE Transactions on Energy Conversion, Vol. 14, No. 4, December 1999, pp. 1391-1395.

[5] J. F. Gieras and M. Wing. Permanent Magnet Motor Technology, Design and Applications. Marcel Dekker, New York 1997. 